\title{
Search for the Optimal Model of Institutional Capacity to Counteract Infectious Threats in the Modern World
}

\author{
Oleksandr T. Zyma, Olha M. Soloviova, Iryna V. Boiko, Valentyna A. Somina, Yuliia V. Mekh \\ Yaroslav Mudryi National Law University, \\ 77 Pushkinskaya Str., 61000 \\ Ukraine
}

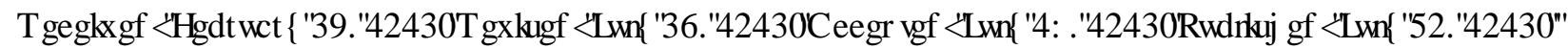

\begin{abstract}
Epidemiological surveillance of public health is an important tool for protection against viral and infectious diseases, both at the national and international levels. Its key role is played by such components as prevention, sanitary protection, compulsory vaccination, audit of the epidemic situation, special anti-epidemic measures, etc. Their implementation requires a systematic approach, which can only be ensured by professional, balanced, and scientifically sound public administration in the field of public health, including on the international scale. The COVID-19 pandemic has exposed a number of issues related to public administration in healthcare and epidemiological surveillance. In this article, the authors analyse the world experience of building systems that ensure sanitary and epidemiological well-being, and try to assess its impact on the effectiveness of counteracting epidemiological threats. In the course of the study, the authors investigated the structure of the system of antiepidemic and sanitary bodies of more than forty countries of the world. The authors have left out countries with a small population (because they are characterised by universalisation, multifunctionality of public administration entities) and countries whose statistics on the spread of COVID-19 are questionable. For others, it was possible to identify three main approaches to building a system of sanitary and anti-epidemic bodies and to propose appropriate models of the institutional mechanism of public administration in the field of epidemiological well-being.
\end{abstract}

Keywords-COVID-19; epidemiological healthcare sector; infectious safety.

\section{INTRODUCTION}

Tn recent years, humanity has faced serious threats to the Ihealth of people not just in one country, but around the world. Such a challenge was the outbreak of coronavirus disease in 2019 (COVID-19) [1], which shocked the world as it spread rapidly from continent to continent and ultimately became a pandemic with millions of infected patients, thousands of deaths, with devastating effects on the world economy. On January 30, 2020, the World Health Organization (WHO) declared an outbreak of this disease an international health emergency [2]. According to the UN, a monthly pandemic costs the global economy 375 billion US dollars [3].

The world community has once again stressed the importance of creating an effective public health system capable of responding to health emergencies, coordinating and implementing anti-epidemic measures. According to UN Secretary-General Antonio Guterres, the COVID-19 pandemic has shown that healthcare, strong public health systems, and emergency preparedness are essential for communities, the economy, and every single person [3]. Undoubtedly, epidemiological surveillance of public health is an important tool for protection against viral and infectious diseases, both nationally and internationally.

Its key role is played by such components as prevention, sanitary protection, compulsory vaccination, audit of the epidemic situation, special anti-epidemic measures, etc. Their implementation requires a systematic approach, which can only be ensured by professional, balanced, and scientifically sound public administration in the field of public health, including on the international scale. The importance of such measures is explained by the fact that today the pandemic is considered not only as a rapid spread of infection but also as a biological catastrophe, which can also be dealt with in terms of disaster management [4]. The main role is given to such measures that can reduce the negative consequences (reduce risk), ensure preparedness for future threats (equip medical 
personnel and the public to an outbreak), respond quickly (control measures and infection treatment), and recover (promote recovery of infected patients and infected health professionals physically, psychologically, and socially) [5].

The COVID-19 pandemic has exposed a number of issues related to public administration in healthcare and epidemiological surveillance. For example, many countries have not yet established a health emergency response system. Even in the countries where it exists, there is a lack of funding, understaffing, which characterises the overall coordination of anti-epidemic work as completely ineffective. This problem is particularly prevalent in developing countries, whose public healthcare systems that must contain new threats are weak and unable to withstand the current burden of disease. Another problem with public healthcare systems in many countries is the lack of adequately trained medical staff and opportunities to control diseases, including a new outbreak of coronavirus [6]. In many countries, healthcare professionals are faced with the problem of lack of personal protection measures [7], which inevitably affects the state of the epidemiological situation in a particular area, as well as the time of its overcoming.

Healthcare systems in countries with low income are suffering from underfunding, lack of health workers, and old infrastructure, with the result that many countries are struggling to provide routine immunisation and healthcare for common diseases, not to mention regular epidemiological surveillance of diseases [8]. Nowadays, the world community has concluded the need to build an effective public health system, represented by a system of bodies capable of responding effectively to new infections, to conduct immediate investigations and corrective measures to prevent outbreaks, and to warn all other countries of the need for preventive measures. Epidemiological surveillance is an important part of the public healthcare system. The Renewed Strategy for combating COVID-19, adopted by WHO on 14 April 2020, states that national health emergency management mechanisms, including a multidisciplinary national coordination structure and event management, need to be implemented to ensure coordinated management of preparedness and response to COVID-19 [9].

The aim of the study is to propose work models of the institutional mechanism of public administration in the field of epidemiological well-being based on the analysis of world experience of building systems that ensure sanitary wellbeing. To achieve this aim, the following tasks were set:

- to investigate the structure of the system of anti-epidemic and sanitary bodies of more than forty countries;

- to identify main world approaches to building a system of sanitary and anti-epidemic bodies;

- to analyze the scientific works in the area;

- to assess the impact of different systems on the effectiveness of counteracting epidemiological threats;

- to propose appropriate models of the institutional mechanism of public administration in the field of epidemiological well-being.

\section{THE ROLE OF EPIDEMIOLOGY IN THE PROVISION OF INFECTIOUS SAFETY OF THE POPULATION}

The term epidemiology comes from the Greek words $\dot{\varepsilon} \pi \delta \eta \mu i ́ \alpha$ - for the people and $\lambda$ ó $\gamma \circ \varsigma$ - doctrine, in other words, defines the doctrine of what is happening to the population. In dictionaries, epidemiology is understood as research on the distribution and determinants related to the health of conditions or events in certain populations, as well as the application of this study to the control of health problems [10]. The main "object of knowledge" of epidemiology as a scientific discipline is the causes and events related to public health. Over the last 70 years, the meaning of the definition has expanded from the study of epidemics of infectious diseases to all processes and phenomena related to health in populations. As early as the mid-1980s, five main tasks of epidemiology in healthcare practice were identified: 1) epidemiological surveillance of public health, 2) field research, 3) analytical research, 4) evaluation, and 5) communication [11]. Recently, another task was added policy development [12]. In turn, such tasks are entrusted to state-authorised entities.

The primary function of epidemiology is to carry out epidemiological surveillance of public health, conventionally defined as the ongoing systematic collection, analysis, interpretation, and dissemination of health data required to plan, implement, and evaluate public health practices, closely integrated with the dissemination of these data among those who need to know about prevention and control [13]. Epidemiological surveillance is carried out to find and describe the patterns of occurrence of potential diseases so that measures of investigation, control, and prevention could be applied effectively and efficiently. Data collection plays an important role in any surveillance system. Data collected through the public health surveillance system can be used to assess the scale of the problem, identify groups of increased risk of deteriorating outcomes, study the relationship between risk factors and consequences, develop interventions and continuously monitor the effectiveness of interventions to change complications or results [14].

Epidemiological surveillance of public health is a tool for assessing the health and behaviour of the population, usually carried out by public institutions, including the Ministry of Health and the Ministry of Finance [15]. Since surveillance can directly measure what is happening to the population, it is useful both for assessing the need for intervention and for directly measuring its outcomes. It is surveillance that provides the basis for the scientific and factual data needed to make reasonable decisions and take appropriate actions in the field of public health. Another function of epidemiology is related to the implementation of epidemiological surveillance - the investigation of cases of the disease and related circumstances, as well as the implementation of field investigations, which helps assess the scale of the epidemic and its causes.

Since there are no geographical or jurisdictional boundaries for the disease, the communication between the epidemiology 
services of different countries is important. National antiepidemiological surveillance entities do not operate in isolation, but instead, they establish links for data exchange at the interstate and supranational scales. Public health epidemiologists regularly provide information, evidence, and guidance on disease control strategies, disease regulations, and enabling states to develop policies and strategies to address the threats caused by infectious diseases. Thus, political decisions by government officials are made based on and taking into account the position of epidemiological services.

The importance of epidemiological surveillance both within each country and for humanity as a whole have been revealed by the COVID-19 pandemic. Governments around the world are responding to the pandemic caused by severe acute coronavirus 2 respiratory syndrome (SARS-CoV-2) with unprecedented policies to slow the growth of infections. A number of restrictive measures, including the closure of schools and restrictions on public access to various facilities, require large and visible costs for society; however, their advantages cannot be observed directly, and currently, they can be understood only through process modelling [16].

Epidemiologists have identified two fundamental strategies for overcoming infectious threats: (a) mitigation, which aims to slow down, but not necessarily stop the spread of the epidemic - reducing the peak demand for medical care while protecting against infection those who are at risk of serious diseases, and (b) suppression, aimed at reversing the growth of the epidemic, reducing the number of cases to a low level and maintaining this situation for an indefinite period. But each of them does not stand up to criticism and is not perfect. Thus, the Imperial College Response Team's report on COVID-19 called for mitigation as the optimal policy, but warnings about hundreds of thousands of deaths due to healthcare overload remain relevant.

It is certain policy decisions aimed at combating the infection, that made it possible to significantly slow down its growth. Some policies affect populations in different ways, but in general, there is strong evidence of the declining spread of the disease and achieving significant, beneficial, and measurable health outcomes [17]. However, as correctly noted, the actual impact of this policy on the level of infection in an ongoing pandemic is unknown [17]. Since the modern world has never encountered such a pathogen or applied a policy of counteracting infection on such a scale, it is critical that direct measurements of policy effects were used in conjunction with numerical simulations in current decisions. Either way, the effective implementation of all these functions by an operational apparatus of public authorities will allow to overcome certain crises in the field of public health at the lowest cost. But the main role should be given to those who carry out public health surveillance.

Pandemic threats have confirmed the risks of national security vulnerabilities for Ukraine. The Constitution of Ukraine binds the state with the obligation to ensure the sanitary and epidemiological well-being of the population.
However, at the beginning of 2020, in Ukraine, public administration in the field of sanitary and epidemiological well-being was not legally carried out by any public authority. Certain unsystematic actions, the legitimacy of which is highly questionable, have been and are being committed by the Ministry of Health $(\mathrm{MoH})$, the Cabinet of Ministers of Ukraine, the State Service of Ukraine for Food Safety and Consumer Protection, and the National Police of Ukraine. In addition, the Ministry of Health of Ukraine has established a Public Health Centre, which is a state institution, the main task of which, among other things, is to carry out epidemiological surveillance (observation), the administration of authority to protect the population from infectious diseases; it is entrusted with scientific-practical and organisationalmethodical functions in the field of public health. The reason for such a situation to occur and the dynamics of its development are a subject of a separate study, while the authors of this study simply note that Ukraine is one of the few countries in the world that failed to establish public administration in this area even in the midst of the COVID-19 pandemic. The disadvantages and shortcomings of such administration are obvious, as is the fact that Ukraine should establish public administration bodies as soon as possible, capable of effectively managing the fight against viral, infectious, and other threats to public health. Its effectiveness would depend on a number of factors: (a) the professionalism of the staff; (b) technical support; (c) the level of funding; (d) the legal framework; (e) public relations and interaction; (e) personal qualities of managers, etc. Among them, the system of anti-epidemiological surveillance bodies, its place in public administration, and relations with other authorities play a significant role.

\section{RESEARCH OF THE INSTITUTIONAL ASPECT OF THE ANTI- EPIDEMIOLOGICAL SURVEILLANCE SYSTEM}

To overcome such a crisis situation, the development of national public administration bodies in the field of infectious disease prevention, epidemic, and sanitary supervision should commence as soon as possible. Thus, on the examples of individual countries, the authors analysed the construction of a public health system aimed at preventing the manifestations of infectious diseases to conclude on their effectiveness. In this study, the authors investigate the world practices of building institutional structures that ensure sanitary and epidemiological well-being and try to assess its impact on the effectiveness of counteracting epidemiological threats. In the course of the study, the authors examined the structure of the system of anti-epidemic and sanitary bodies of more than forty countries of the world. The countries with a small population were left out (because they are characterised by universalisation, multifunctionality of public administration entities) and countries whose statistics on the spread of COVID-19 are questionable. For others, it was possible to identify three main approaches to building a system of sanitary and anti-epidemic bodies and to propose appropriate models of the institutional mechanism of public administration 
in the field of epidemiological well-being (Table 1).

TABLE I. MODELS OF THE INSTITUTIONAL MECHANISM OF PUBLIC ADMINISTRATION IN THE FIELD OF EPIDEMIOLOGICAL WELLBEING

\begin{tabular}{|c|c|c|}
\hline $\begin{array}{l}\text { Institutional mechanism } \\
\text { models }\end{array}$ & Description & Countries \\
\hline Model 1 & $\begin{array}{l}\text { It is a model where anti-epidemiological surveillance is performed directly by } \\
\text { the Ministry of Health or its analogue }\end{array}$ & $\begin{array}{l}\text { Israel, Argentina, Brazil, } \\
\text { Italy, Republic of Belarus, } \\
\text { US }\end{array}$ \\
\hline Model 2 & $\begin{array}{l}\text { It is a model in which public administration in the field of epidemiological well- } \\
\text { being is carried out by the Ministry of Health or its analogue and a number of } \\
\text { subordinates, but organisationally separated bodies. }\end{array}$ & $\begin{array}{l}\text { Norway, Sweden, Germany, } \\
\text { Great Britain, New Zealand }\end{array}$ \\
\hline Model 3 & $\begin{array}{l}\text { The epidemiological well-being is ensured by a separate specialised body under } \\
\text { the Ministry of Health. }\end{array}$ & $\begin{array}{l}\text { Poland, South Korea, } \\
\text { Georgia, China, Ukraine, }\end{array}$ \\
\hline
\end{tabular}

\section{A. First Model}

It is a model where anti-epidemiological surveillance is performed directly by the Ministry of Health or its analogue. In this case, managerial responsibilities are vested in one or more structural units of the ministry, the activities of which are directed by the minister or through one of their deputies. For example, in Israel, the Department of Epidemiology and, partly, the Laboratory Department of the Ministry of Health of Israel deal with issues of sanitary and epidemiological wellbeing. Moreover, the activities of both public and private laboratory institutions are directed through the laboratory department [18]. The situation is similar in Argentina and Brazil. In the first country, public administration in this area is carried out through the National Office of Epidemiology and Strategic Information, and the Office of Immunisation and Disease Prevention of the Ministry of Health of Argentina [19]. In the second one, less attention is paid to epidemic wellbeing, and administration is done through the Secretariat of Health Supervision of the Brazilian Ministry of Health, which replaced the National Epidemiological Centre, which had certain organisational autonomy [20].

In Italy, the situation is more complicated. The Ministry of Health also plays a central role in public administration in the field of epidemiology. The Ministry consists of the High Council of Health - a scientific and technical advisory body to the Minister. One of its sections deals mainly with issues of prevention, sanitation, and epidemiology (notably, that a very common, regardless of the approach to administration, is a combination of prevention and sanitation in the field of one body or its structural unit). Admittedly, this section does not make management decisions unassisted, but it is capable of exerting intense influence on the minister in the process of shaping public policy. One of the basic branches of the ministry is the Main Department of Prevention. It directly carries out epidemiological surveillance, administration of laboratory practice, solves problems of sanitary supervision, hygiene, issues of prevention and proactive measures on the spread of viral, infectious, and other mass diseases. The collegial body of the ministry, the National Centre for Disease Prevention and Control works closely with this branch. It mainly coordinates the work on prevention, hygiene, sanitary and epidemiological well-being at the local level, and coordinates the activities of municipal bodies and healthcare institutions with state policy. In addition, the National Centre responds to health emergencies [21].

The Soviet approach has been preserved in the Republic of Belarus. The executive body that administers sanitary and epidemiological threats is the Ministry of Health. The First Deputy Minister is the Chief Sanitary Doctor of the Republic of Belarus. He heads the system of sanitary supervision, the so-called "sanitary service". Its centre is the Department of Hygiene, Epidemiology and Prevention of the Ministry of Health. In addition, the sanitary service includes state institutions and local authorities. In this case, they are all part of the Ministry of Health or directly subordinate to it [22]. Surprisingly, we see a very similar situation in the United States. The Department of Health and Social Services (similar to the Ministry of Health) is a body that formulates policies in the field of sanitary and epidemiological well-being [23]. Direct administration in this area is carried out through the Centre for Disease Control and Prevention. It performs administration in the field of epidemiological surveillance, infection control, general hygiene, prevention, laboratory work and laboratory research, etc. [24].

\section{B. Second Model}

It is a model in which public administration in the field of epidemiological well-being is carried out by the Ministry of Health or its analogue and a number of subordinates, but organisationally separated bodies. In Norway, for example, the Ministry of Health and Social Welfare handles certain issues of sanitation and epidemiology through its unit, the Department of Public Health. However, most of the authority in this area is vested in its subordinate body, the Norwegian Institute of Public Health (NIPH), and, more specifically, in one of its units, the Department of Epidemic Control and Environmental Hygiene. Some responsibilities were transferred to other bodies subordinate to the Ministry [25].

A similar situation has developed in Sweden. The Ministry of Health and Social Affairs also has a number of responsibilities in the field of epidemiology. It also directs the activities of 17 bodies. At least three of them have some authority to ensure sanitary and epidemiological well-being. 
These include the Swedish Institute for Infectious Disease Control; The Swedish National Institute of Public Health and the Swedish National Council for Health and Welfare. Interestingly, the Swedish Ministry of Health and Social Affairs did not envisage the involvement of the Swedish Institute for Infectious Disease Control in developing the COVID-19 coronavirus outbreak programme but instead called for the involvement of two non-subordinate bodies: the Medical Products Agency and the Swedish Civil Emergency Agency [26].

In Germany, public administration in this area is carried out by the Federal Ministry of Health. Its structure is quite complex and branched, and some responsibilities to combat epidemics, laboratory practice, prevention, sanitation are distributed among several departments. The authors were unable to identify the dominant among them [27]. However, the existing system of sanitary and anti-epidemic bodies in this country was classified as the second group, because in addition to the German Ministry of Health, the authority to counter epidemic threats is given to two institutions subordinate to it. These are the Robert Koch Institute and the Federal Centre for Health Education. They are not subjects of public administration per se, but they are entrusted with certain administrative functions, they are delegated certain powers, and they contribute to ensuring sanitary and epidemiological well-being in other, non-governmental aspects. The Robert Koch Institute is a scientific institution that is primarily engaged in research in the field of epidemiology. It has also been given (delegated) several administrative powers to conduct epidemiological surveillance and collect official statistics [28]. The Federal Centre for Sanitary Education is a state body that, on the one hand, develops and implements government programmes in various fields, including those related to combating viral diseases, tuberculosis, donor promotion, etc., and, on the other hand, forms a wide database network on issues of sanitation and prevention needed by ordinary citizens [29].

In Great Britain, the construction of the system of public administration is complicated by the specifics of its administrative-territorial division. As in Norway, part of the authority to ensure epidemic well-being is vested in the Ministry of Health and Social Welfare. Together with it, the Anguilla Public Health Agency, which is one of the main working bodies of the Ministry and endowed with operational autonomy, deals with this issue. However, its activities, as the name implies, extend only to the territory of Anguilla. As for similar bodies in Scotland, Wales, and Northern Ireland, the Ministry cooperates with them in a different way. In addition, certain issues of sanitary and epidemiological well-being are dealt with by other bodies subordinated to the Ministry (29 such bodies in total) [30]. During the work, the authors of the article were not able to establish how the administration is carried out in the field of sanitary and epidemiological wellbeing in the overseas territories of Great Britain, such as England.

The model used in New Zealand is similar to the British, but the emphasis is somewhat shifted. The Ministry of Health of New Zealand pays a lot of attention to broad immunisation, organises vaccination of various categories of the population. There are also national measures to combat various viral diseases, constant control, and counteraction to infectious diseases, etc. Part of the authority for the administration of the sanitary-epidemiological sphere is divided between three bodies subordinated to the Ministry, and none of them is focused exclusively or mainly on sanitary and anti-epidemic activities [31]. For example, the New Zealand Health and Safety Commission is a government agency that oversees a wide range of different government programmes. It makes problems monitoring, develops programmes, and ensures and facilitates their implementation using mostly soft methods. One of these programmes is infection prevention and control, which currently covers six separate projects [32].

The New Zealand Health Research Council is a collegial body appointed by the Minister for Health. It sets research priorities in the field of healthcare and initiates research, including those related to epidemiological safety. In essence, this body organises and ensures investment in research at the expense of the state budget and otherwise, as well as controls the conduct of research and the use of funds. It was the Health Research Council that announced on April 17, 2020, funding for three clinical trials of potential COVID-19 treatments. The Health Promotion Agency is a body focused on marketing, information, and organisational activities in New Zealand on hygiene, prevention, etc. A considerable part of their research, campaigns, and programmes are directly or indirectly related to sanitary and epidemiological well-being [34].

\section{Third Model}

In the third model, the epidemiological well-being is ensured by a separate specialised body under the Ministry of Health. A typical example is Poland. The State Sanitary Inspectorate, headed by the Chief Sanitary Doctor of the country, is an independent body, the activities of which are directed by the Ministry of Health. A wide range of powers has been transferred to the inspection. It provides not only sanitary protection and sanitary supervision but also the promotion of a healthy lifestyle, controls the quality of food, etc. [35]. In South Korea, the Ministry of Health and Welfare is a body focused primarily on coordinating health activities and has limited influence over other public administration entities. The central role here is played by an independent public administration entity, the Korean Centre for Disease Control and Prevention. Out of its nine specialised units, three are exclusively concerned with epidemiology, and three others are involved in addressing these issues and addressing specific health issues. In essence, this is a kind of Korean sanitaryepidemiological inspection [36]. A similar approach can be observed in Japan.

In Georgia, the Ministry of Temporary Displaced Persons, Labour, Health, and Social Welfare, among other things, deals with epidemiological administration. However, its powers in this area are not limited, but fragmentary [37]. The Ministry 
has a National Centre for Disease Control and Public Health. This body is engaged in scientific activities, but at the same time is the administrator of the laboratory network of the country and implements a number of government programmes, including the programme of epidemiological control [38]. However, in the authors' opinion, the level of administration in the field of ensuring sanitary and epidemiological well-being in this country is quite low, possibly the closest to Ukraine. These institutional models of public administration in the field of anti-epidemiological surveillance are not exhaustive and comprehensive. Some states have formed their own views on the administration of sanitary and epidemiological well-being.

For example, in China, there is a rather complex three-level model. The administration of healthcare, including sanitary and epidemiological well-being, is carried out by the National Health Commission of China (analogue and historical successor of the Ministry of Health). Among other things, it is authorised to develop and implement plans for preventive measures, the National Immunisation Programme; to determine the system of measures to counteract significant threats to public health; to regulate the procedure for quarantine and monitoring of infectious diseases; monitor compliance with hygiene standards, etc. Its main role is played by its divisions, such as the Office of Disease Prevention and Control, the Office of Inspection and Surveillance, and the Centre for Public Health Emergency Management [39].

The Chinese National Centre for Disease Control and Prevention, which is officially called the technical state body, reports to the National Health Commission of China. In essence, it is a corporation that brings together a variety of government agencies and organisations focused on ensuring the proper level of public health. It would be logical if these institutions had a scientific or educational focus, but this is not entirely true. For example, the National Institute for the Control and Prevention of Viral Diseases performs four functions: responding to emergencies, controlling and preventing viral diseases, conducting research, and conducting training and educational activities. Obviously, the implementation of the first two functions requires administrative powers. The National Institute for Infectious Disease Control and Prevention works closely with and essentially ensures the activities of China's National Health Commission for Epidemiological Surveillance. Other components of the Chinese Centres for Disease Control and Prevention are involved in public administration in other ways [40-44]. In Russia, on the contrary, everything is extremely simplified. The public administration of sanitary and epidemiological well-being is entrusted to the Federal Service for Supervision of Consumer Protection and Human Welfare, which is not related to the Ministry of Health at all.

Nowadays, not only the WHO but also many countries that have suffered from the negative effects of coronavirus infection, are looking for optimal approaches not only to apply measures to combat the infection but also to create an effective institutional system for such control. Instead, in any case, the introduction of an effective model of public administration is only one of the elements of the mechanism of counteraction to infectious diseases and the implementation of anti-epidemic functions. The thesis is also important given that, according to WHO Director-General Tedros Adhanom Ghebreyesus, "history convinces us that this pandemic will not be the last, and that epidemics are normal life events". The UN General Assembly has adopted a resolution calling for greater global solidarity and international cooperation fighting against the coronavirus pandemic.

\section{CONCLUSION}

Using the data on the level of prevalence of COVID-19 the number of patients per 1,000 people, the country shows a fairly clear correlation. The highest incidence rates are in countries that use the first model of administration in the field of epidemiological well-being (Israel - 34.7; USA - 28.3; Argentina - 26.6; Brazil - 26.3). In contrast, none of the countries using the second and third models exceeded the limit of 20 patients per thousand people. The lowest rates among those analysed can be seen in New Zealand - 0.4; South Korea -0.5 ; Japan -0.8 , Norway -4 . The above-mentioned information allows to formulate the following conclusions.

Firstly, the lowest efficiency in the fight against the COVID-19 pandemic is shown by the states where public administration in the field of ensuring sanitary and epidemiological well-being is carried out through the relevant structural units of the Ministry of Health. Secondly, in Ukraine, systematic public administration in the field of antiepidemiological surveillance is not carried out; instead, there are some unsystematic actions. The introduction of any system of real public administration will yield positive results in counteracting the pandemic. Thirdly, coronavirus disease is more effectively counteracted by states where public administration in the field of epidemic security is carried out by several or one independent state body subordinated to the Ministry of Health. Fourthly, for Ukraine, there is a typical system when the administration in this area is carried out by one subordinate body of the Ministry of Health (model of Poland, South Korea). In addition, there is a legal basis for the introduction of such a model. Similar assumptions about the impact of the model of institution-building of public administration entities in the field of anti-epidemiological surveillance on the incidence rate of COVID-19 are relevant not only for Ukraine.

\section{ACKNOWLEDGMENT}

None.

\section{References}

[1] E. Edwards, (2020), Coronavirus Gets official name from WHO: COVID-19. [Online] https://www.kget.com/health/coronavirus-gets-officialname-from-who-covid-19/ 
[2] Statement on the second meeting of the International Health Regulations (2005) Emergency Committee regarding the outbreak of novel coronavirus (2019$\mathrm{nCoV})$ (2020).

[Online] https://www.who.int/news/item/30-01-2020-statementon-the-second-meeting-of-the-international-healthregulations-(2005)-emergency-committee-regarding-theoutbreak-of-novel-coronavirus-(2019-ncov)

[3] A. Guterres, (2020), We all must learn from this crisis. [Online] https://www.un.org/ru/coronavirus/scaleinvestment-universal-health-coverage-and-strongerhealth-systems

[4] D. Wing-KeungChan, "A reflection on the anti-epidemic response of COVID-19 from the perspective of disaster management," Int. J. Nurs. Sci., vol. 7 no. 3 pp. 382-385, 2020.

[5] ICN Framework of Disaster Nursing Competencies. (2009).

[Online] http://www.apednn.org/doc/resourcespublications/ICN\%2 0Framework\%20of\%20Disaster\%20Nursing\%20Compet encies\%20ICN\%202009.pdf

[6] G. Mitchell, (2020), Not enough' intensive care nurses for coronavirus outbreak. [Online] https://www.nursingtimes.net/news/hospital/not-enoughintensive-care-nurses-for-coronavirus-outbreak-12-032020/

[7] J. Nandi, (2020), Lack of PPE, poor infection control put medical staff at risk of Covid-19. [Online] https://www.hindustantimes.com/india-news/lack-of-ppepoor-infection-control-put-medical-staff-at-risk-of-covid19/story-5jmeJgwUAaFuu4wfiCu8XN.html

[8] S. H. Qari, H. R. Yusuf, S. L. Groseclose, M. R. Leinhos, and E. G. Carbone, "Public health emergency preparedness system evaluation criteria and performance metrics: a review of contributions of the CDC-funded preparedness and emergency response research centers," Disaster Med. Publ. Health Prep., vol. 13, no. 3, pp. 626638, 2019.

[9] Updated strategy to combat the COVID-19. (2020). [Online] https://www.who.int/ru/emergencies/diseases/novelcoronavirus-2019/strategies-plans-and-operations

[10] J. M. Last, Dictionary of epidemiology. New York: Oxford University Press, 2001.

[11]S. Gale, and K. M. Keyes, "Epidemiology at the Heart of Population Health Science". Am. J. Epidemiol., vol. 188, no. 5, pp. 883-885, 2019.

[12]R. Popat, and J. Simard, "Principles of clinical epidemiology", In: R.J. Wong, R.G. Gish (Eds.), Clinical Epidemiology of Chronic Liver Diseases (1-15). New York: Springer International Publishing, 2018.

[13] J. J. Hamilton, K. Turner, and M. Lichtenstein Cone, "Responding to the pandemic: Challenges with public health surveillance systems and development of a COVID-19 national surveillance case definition to support case-based morbidity surveillance during the early response,” J. Publ. Health Manage. Pract., no. 27, pp. S80-S86, 2021.
[14]E. C. Lee, A. Arab, S. M. Goldlust, B. T. Grenfell, and S. Bansal, "Deploying digital health data to optimize influenza surveillance at national and local scales," PLoS Comput. Biol., vol. 14, no. 3, article number e1006020, 2018.

[15]M. Edelstein, L. M. Lee, A. Herten-Crabb, D. L. Heymann, and D. R. Harper, "Strengthening global public health surveillance through data and benefit sharing," Emerging Infect. Dis., vol. 24 no. 7, pp. 1324-1330, 2018.

[16]N. M. Ferguson, D. Laydon, and G. Nedjati-Gilani, (2020). Report 9: Impact of non-pharmaceutical interventions (NPIs) to reduce COVID-19 mortality and healthcare demand. [Online] https://www.imperial.ac.uk/media/imperialcollege/medicine/mrc-gida/2020-03-16-COVID19Report-9.pdf

[17] S. Hsiang, D. Allen, and S. Annan-Phan, "The effect of large-scale anti-contagion policies on the COVID-19 pandemic," Nature, vol. 584, pp. 262-267, 2020.

[18] Ministry of Health, State of Israel. (2021). [Online] https://www.health.gov.il/Russian/UnitsOffice/HD/PH/ep idemiology/Pages/default.aspx

[19] Ministry of Health (Argentina). (2021). [Online] https://www.argentina.gob.ar/salud

[20] Health Surveillance Secretariat (Brazil). (2021). [Online] https://www.gov.br/saude/pt-

br/composicao/secretarias/secretaria-de-vigilancia-emsaude

[21]Ministry of Health (Italy). (2021). [Online] http://www.salute.gov.it/portale/ministro/p4_2.html

[22] Sanitary Service of the Ministry of Health of Belarus. (2021).

[Online]

http://minzdrav.gov.by/ru/ministerstvo/struktura/sanitarna ya-sluzhba/index.php

[23] The Department of Health and Human Services (USA). (2021).

[Online] https://web.archive.org/web/20041015024526/http://www .hhs.gov/about/whatwedo.html

[24] CDC Organization. (2021). [Online] https://www.cdc.gov

[25]Division of Infection Control and Environmental Health. (2021). [Online] https://www.fhi.no/en/about/this-is-thenorwegian-institute-of-public-health/divisions/infectioncontrol-environmental-health/

[26] Ministry of Health and Social Affairs. (2021). [Online] https://www.government.se/press-releases/2020/07/planfor-the-event-of-new-outbreaks-of-covid-19/

[27]Federal Ministry of Health. (2021) [Online] https://www.bundesgesundheitsministerium.de/

[28] The Robert Koch Institute. (2021). [Online] https://www.rki.de/EN/Content/Institute/institute_node.ht $\mathrm{ml}$

[29] The Federal Center for Health Education is a specialist authority within the portfolio of the Federal Ministry of Health. (2021). [Online] https://www.bzga.de/ueber-uns/

[30]Departments, agencies and public bodies. (2021). [Online] https://www.gov.uk/government/organisations

[31] Ministry of Health - Manatū Hauora. (2021). [Online] https://www.health.govt.nz/ 
[32] Health Quality and Safety Commission of New Zealand. (2021). [Online] https://www.hqsc.govt.nz/

[33] Health Research Council of New Zealand. (2021). [Online] https://www.hrc.govt.nz/

[34] Health Promotion Agency. (2021). [Online] https://www.hpa.org.nz/

[35] The State Sanitary Inspection. (2021). [Online] https://www.gov.pl/web/gis/podstawowe-informacje.

[36] Korea Disease Control and Prevention Agency. (2021). [Online] http://www.cdc.go.kr/contents.es?mid=a30109010000

[37] Ministry of Labor, Health and Social Affairs of Georgia. (2021). [Online] https://www.moh.gov.ge/ka/706/

[38] National Center for Disease Control and Public Health (Georgia). (2021). [Online] https://www.ncdc.ge/Pages/User/Documents.aspx?ID=27 6f72b9-17b5-4145-8fc1-eb72ef0b4f6a

[39] National Health Commission of the PRC. (2021). [Online] http://en.nhc.gov.cn

[40]Chinese Center for Disease Control and Prevention. (2021). [Online] http://www.chinacdc.cn/en/

[41]O. Golubov. (2020). WHO Director-General: Coronavirus is not the last pandemic. [Online] https://www.dw.com/uk/hendyrektor-vooz-koronavirustse-ne-ostannia-pandemiia/a-56066365

[42]F. Guias, "Effects of the reproduction number in a SEIIRD model describing the time evolution of COVID19 at country level," WSEAS Trans. Comp., vol. 19, pp. 292-297, 2020.

[43]C. Chua, and N. S. Ruzgar, "Perceptions of business students toward online education before and in transition period of COVID-19," WSEAS Trans. Comp., vol. 19, pp. 242-261, 2020.

[44] K. R. El Helow, and A.-B. M. Salem, "Are Artificial Intelligence (AI) and Machine Learning (ML) Having an Effective Role in Helping Humanity Address the New Coronavirus Pandemic?" WSEAS Trans. Biol. Biomed., vol. 17, pp. 119-124, 2020.

\section{Author Contributions:}

Oleksandr T. Zyma: Conceptualization, Investigation, Formal analysis and Writing - original draft.

Olha M. Soloviova: Investigation, Formal analysis and Writing - original draft and Writing - review \& editing. Iryna V. Boiko: Investigation, Formal analysis and Writing - original draft and Writing - review \& editing. Valentyna A. Somina: Investigation, Formal analysis and Writing - original draft and Writing - review \& editing.

Yuliia V. Mekh: Investigation, Formal analysis and Writing - original draft and Writing - review \& editing.

\section{Creative Commons Attribution License 4.0 (Attribution 4.0 International, CC BY 4.0)}

This article is published under the terms of the Creative Commons Attribution License 4.0

https://creativecommons.org/licenses/by/4.0/deed.en_US 